\title{
The Rheological Properties of Fluid Denture-Base Resins
}

S. G. Vermilyea, J. M. Powers, and A. Koran

Division of Dental Materials, U.S. Army Institute of Dental Research, Walter Reed Army Medical Center, Washington, D.C. 20012, USA, and Department of Dental Materials, University of Michigan, School of Dentistry, Ann Arbor, Michigan 48109, $U S A$

The rheological properties of six commercial fluid denture resins were determined by rotational viscometry. Initial viscosity ranged from 67 to 575 centipoise at a rotational speed of 10 revolutions per minute. All resins showed initial non-Newtonian flow behavior and increased viscosity with time.

J Dent Res 57(2): 227-231, February 1978.

The use of pour-type (fluid) resins for the fabrication of denture bases has increased markedly over the past decade. Advantages offered by the fluid resins include: (1)

Received for publication March 31, 1977.

Accepted for publication August 31, 1977.

Commercial materials and equipment are identified in this report to specify the experimental procedure. Such identification does not imply official recommendation or endorsement or that the equipment and materials are necessarily the best available for the purpose. reduction of processing time; (2) simplification of flasking and deflasking procedures; and (3) reduction of time required for finishing and polishing the cured prostheses. ${ }^{1}$

Previous studies on fluid resins have been addressed to measurement of physical and mechanical properties, modification and refinement of processing procedures, and assessment of the effect of investment materials on the quality of the finished restoration. ${ }^{2-8}$ Products made from pour-type resins often exhibit voids and other surface imperfections. It has been suggested that the defects may be the result of pouring a resin that is too viscous. ${ }^{5}$ Unfortunately, sufficient information regarding the viscous properties of the pour resins is not available.

The present investigation was conducted to determine the apparent viscosity of several pour-type denture base resins as a

TABLE 1

Materials Evaluated in The STUdy

\begin{tabular}{|c|c|c|c|c|c|}
\hline \multirow[b]{2}{*}{ Code } & \multirow[b]{2}{*}{ Material } & \multicolumn{2}{|c|}{ Batch Number } & \multirow{2}{*}{$\begin{array}{l}\text { Powder/Liquid } \\
\text { Ratio by Volume }\end{array}$} & \multirow[b]{2}{*}{ Manufacturer } \\
\hline & & Powder & Liquid & & \\
\hline A & Hyflo & 061776 & 061776 & $2.5 / 1$ & $\begin{array}{l}\text { Hygenic Dental Mfg. Co. } \\
\text { Akron, Oh } 44310\end{array}$ \\
\hline B & Pronto II & 249106 & 069204 & $2.5 / 1$ & $\begin{array}{l}\text { Vernon-Benshoff Co. } \\
\text { Albany, NY } 12201\end{array}$ \\
\hline $\mathrm{C}$ & Pro-Fit & 084040 & 104013 & $2.5 / 1$ & $\begin{array}{l}\text { Howmedica, Inc. } \\
\text { Chicago, Il } 60632\end{array}$ \\
\hline D & Porit & PO372J & MO475C & $2.35 / 1$ & $\begin{array}{l}\text { Product Research Laboratory } \\
\text { Cambridge, Ma } 02130\end{array}$ \\
\hline $\mathbf{E}$ & TruPour & 74226 & 74275 & $2.15 / 1$ & $\begin{array}{l}\text { Dentsply International, Inc. } \\
\text { York, Pa } 17404\end{array}$ \\
\hline $\mathrm{F}$ & Pour-n-Cure & 040476 & 020176 & $2 / 1$ & $\begin{array}{l}\text { Coe Laboratories, Inc. } \\
\text { Chicago, Il } 60658\end{array}$ \\
\hline
\end{tabular}


Fig 1. - The change in viscosity with time at $10 \mathrm{rpm}$.

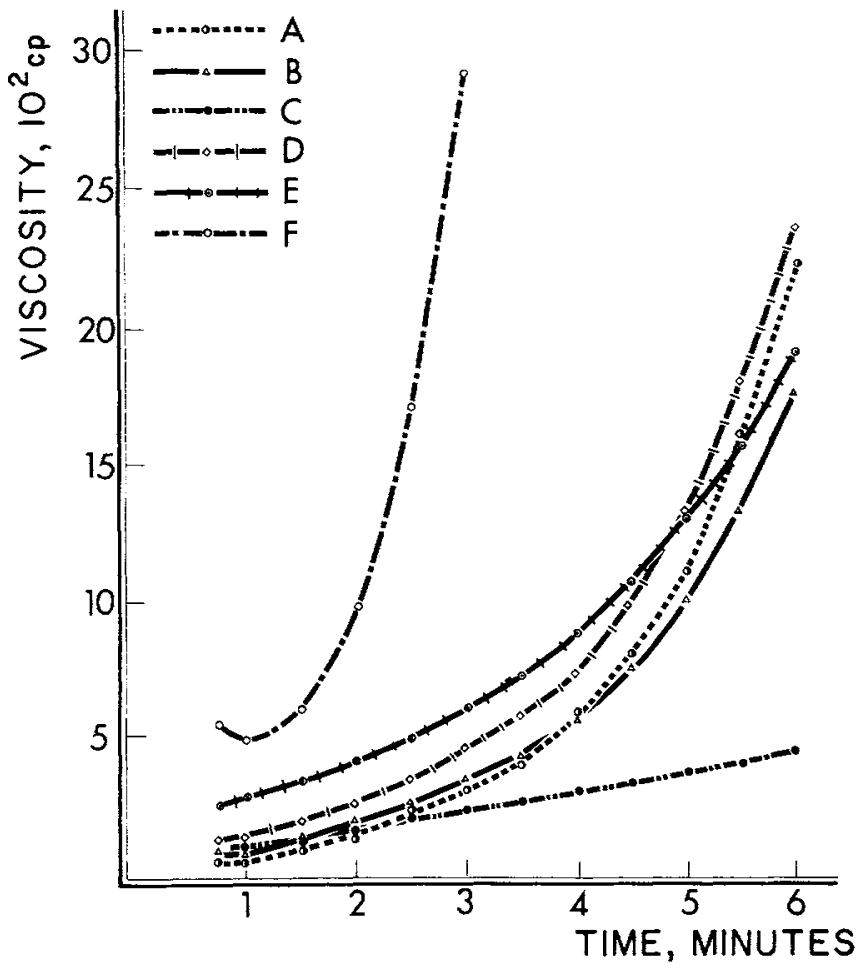

Shearing was caused by the rotation of a disk (diameter $2.12 \mathrm{~cm}$ ) and rod (diameter $0.45 \mathrm{~cm}$ ) spindle assembly ${ }^{\dagger}$ at rates of 10 , 20 , and 50 revolutions per minute (rpm). Three trials were made with each material at each shear rate. The pneumatic output of the viscometer was converted to an electrical signal by a pneumatic-electric converter ${ }^{+}$and recorded on a y-time recorder. $\$$ Data were obtained as viscosities in centipoise (cp) by calibration of the spindle with a Newtonian standard. ${ }^{+} \mathrm{Re}-$ cording of the viscosities of five materials (A, B, D, E, F) was begun 45 seconds after the start of mixing. The long mixing time required for material $\mathrm{C}$ necessitated initial viscosity measurement 90 seconds after commencement of sample preparation. The viscosity of each material was recorded continuously for a period of six minutes following the initiation of mixing or until the viscosity of the mix exceeded the range of the recorder.

All data were evaluated statistically by analysis of variance and means compared using Scheffe's method at the $95 \%$ level of confidence. $^{9}$ 


\section{Results}

The viscosity of each material increased markedly with time. The changes in the viscosities of the resins with time at $10 \mathrm{rpm}$ are shown in Figure 1. Initial viscosity values ranged from $67 \mathrm{cp}$ for material $A$ to $575 \mathrm{cp}$ for material $\mathrm{F}$. The mean values of the initial viscosity at $10 \mathrm{rpm}$ of $\mathrm{C}$ and $\mathrm{D}$ were equivalent (Table 2 ). The mean values of the viscosity of $A, B, D$, and $F$ were statistically different from each other and from those of the other materials at this rotational speed. The Scheffé interval was 21 cp.

Subsequent values were recorded at times when comparable amounts of shear had occurred in each material (3 minutes for $A, B, D, E$, and $F$ and $31 / 2$ minutes for C). At this time, the viscosity of $F$ had increased to $2,900 \mathrm{cp}$ (Table 2). The viscosities of the other materials had increased to values only slightly above $(625 \mathrm{cp}, \mathrm{E})$ or markedly below $(283 \mathrm{cp}, \mathrm{C})$ the initial viscosity of $F(575 \mathrm{cp})$. The mean values of the viscosity of $A, B$, and $C$ were statistically equivalent at the $95 \%$ level of confidence. The viscosities of $B$ and $D$ were also equivalent at this confidence level. The Scheffé interval was $129 \mathrm{cp}$.

The effect of rotational speed on the initial viscosity of the resins is shown in Figure 2. Materials A, B, C, D, and E demonstrated significant increases in viscosity with increased rotational speeds. Material F ex- hibited shear thinning over the range of rotational speeds employed. The Scheffé interval was $11 \mathrm{cp}$. As the time from the start of mixing increased, the effect of rotational speed on the viscosity of all but one of the resins $(F)$ decreased. The changes in viscosity with rotational speed at 3 minutes after the start of mixing are shown in Figure 3. Materials A, B, C, and D behaved as Newtonian liquids with no increase in viscosity with increased rotational speed, whereas materials $E$ and $F$ exhibited shear thinning. The Scheffé interval was $66 \mathrm{cp}$.

\section{Discussion}

The viscosity of a polymerizing monomer-polymer mixture is affected by many factors. The particle size, molecular weight, and initiator content of the polymer as well as the molecular weight, and presence of cross-linking agents, inhibitor and accelerator in the monomer influence the rate of polymerization and contribute to the viscous properties of the mixed resins.

A range of viscosities for the optimal clinical use of the pour resins has not been established. However, the viscosity of the mixed resins as the time from the start of mixing increases would appear to be an important factor in the clinical handling of these materials. A resin possessing a low viscosity for a suitable period of time would be convenient when multiple molds are to be poured from a single mix.

TABLE 2

APPARENT VISCOSITY OF THE FLUID RESINS AT 10 RPM

\begin{tabular}{ccc}
\hline \hline Material & Initial Viscosity $(\mathrm{cp})^{*}$ & Subsequent Viscosity $(\mathrm{cp}) \dagger$ \\
\hline A & $67(14)_{\ddagger}^{\ddagger}$ & $342(29)_{\ddagger}^{+}$ \\
B & $104(7)$ & $371(8)$ \\
C & $133(14)$ & $283(38)$ \\
D & $133(14)$ & $475(25)$ \\
E & $267(29)$ & $625(43)$ \\
F & $575(0)$ & $2,900(260)$ \\
\hline
\end{tabular}

*Values for $A, B, D, E$, and $F$ at 45 seconds after addition of polymer powder to monomer. Value for $\mathrm{C}$ abtained 90 seconds after polymer to monomer addition.

+Values for A, B, D, E, and F at 3 minutes after addition of polymer powder to monomer. Value for $\mathrm{C}$ obtained at $3 \frac{1}{2}$ minutes after polymer to monomer addition.

¥Means with standard deviations in parentheses are based on three trials. Scheffe intervals were $21 \mathrm{cp}$ and $129 \mathrm{cp}$ for initial viscosities and subsequent viscosities respectively. The standard deviation of material $F$ is much different from those of the other materials. The inclusion of this mater. ial in the analysis of variance results in a calculated Scheffe interval that is much larger than would be expected if material $F$ were excluded from the statistical treatment. Hence the calculat. ed Scheffe interval does not discriminate small differences between materials. 
Fis 2. - The initial viscosity of each material as a function of rotational speed.

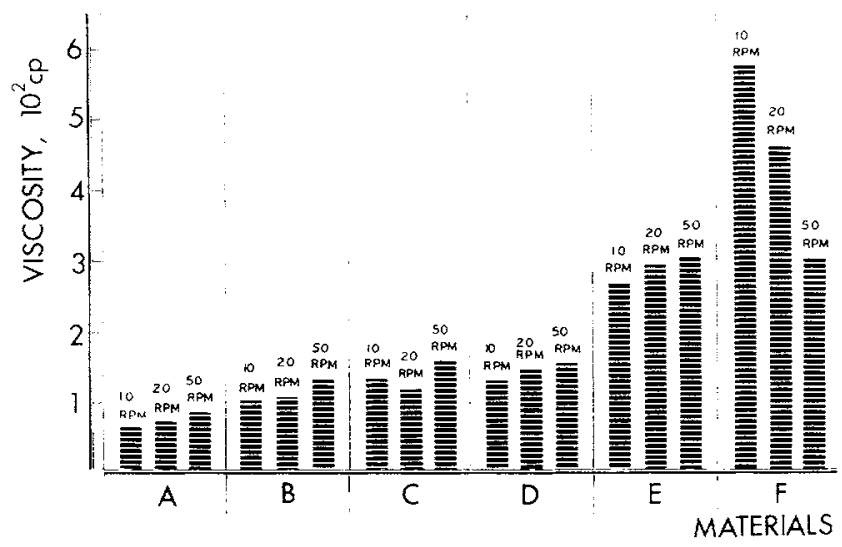

FIG 3. -- The viscosity of each material at 3 minutes after the beginning of mixing as a function of rotational speed.
The initial shear thickening behavior of the fluid resins $A, B, C, D$, and $E$ suggests that the introduction of the mixed resin into the mold should be accomplished slowly. Rapid pouring or injection of these materials may create high shear rates and increase the viscosity such that flow into the fine details of the mold is prohibited.

On the other hand, the shear thinning observed with material $F$ suggests rapid pouring of the resin may enhance the flow into the fine details of the mold. The clinical significance of the shear rate effect is unclear. To date, sufficient information on the rates of shear employed in the clinical handling of these materials is unavailable. Further research into the magnitude of these shear rates and their effects on the detail reproduction and mechanical properties of the fluid resins would be invalu- able in establishing guidelines for the use of these materials.

\section{Conclusion}

Variation in the initial viscosity of six fluid denture base resins was demonstrated by rotational viscometry. All materials showed increases in viscosity with time; however, one material increased at a markedly faster rate.

Five materials exhibited increases in viscosity with increased rotational speed.

Early introduction of the mixed materials into the prepared mold may help minimize the presence of voids and the loss of fine detail in the final restoration.

The cooperation of Coe Laboratories. Hownedica, Inc. and Products Research Laboratories for supplying commercial products is acknowledged. 


\section{References}

1. Winkler, Sheldon: Construction of Denture Bases from Pour Resins, Dent Clin N $A, 19: 243 \cdot 254,1975$.

2. CivjaN, S.; HUGET, E. F.; and DE Simon, L. B.: Modifications of the Fluid Resin Technique, $J A D A, 85: 109-112,1972$.

3. Goodend, R. J., and SChuelte, R. C.: Dimensional Accuracy of Pour Acrylic Resin and Conventional Processing of Cold-Curing Acrylic Resin Bases, $J$ Prosthet Dent, 24:662-668, 1970.

4. Mirza, F. D.: Dimensional Stability of Acrylic Resin Dentures, $J$ Prosthet Dent, 11:848-857, 1961 .

5. Winkler, S.; ORTMAN, H. R.; MORRIS, H. F.; and Plezia, R. A.: Processing
Changes in Complete Dentures Constructed from Pour Resins, JADA, 82:349-353, 1971.

6. Shepard, W. L.: Denture Bases Processed from a Fluid Resin, $J$ Prosthet Dent, 19:561-572, 1968.

7. WinkLeR, S.; MORRIS, H. F.; THONGTHAMMACHAT, S.; and SHORR, J. H.: Investing Mediums for Pour Resins, JADA, 83:848-851, 1971.

8. Koblitz, F. F.; SMITH, R. A.; and WOLFe, H. E.: Fluid Denture Resin Processing in a Rigid Mold, $J$ Prosthet Dent, 30:339-346, 1973.

9. GUenther, W. C.: Analysis of Variance. Englewood Cliffs, N.J.: Prentice-Hall, Inc., 1964, p 141. 